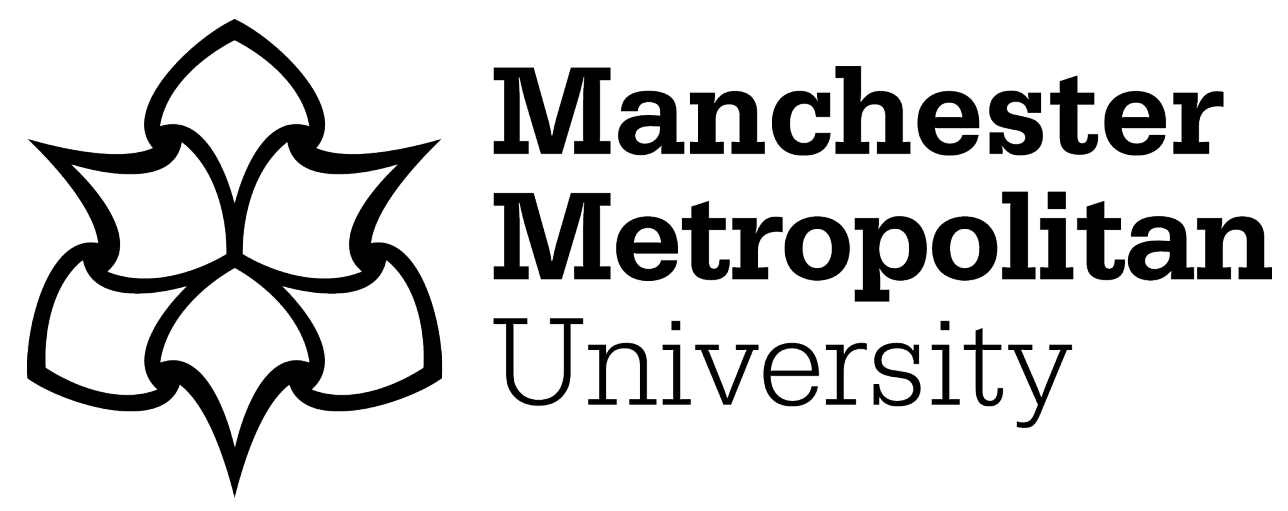

Yeowell, G ORCID logoORCID: https://orcid.org/0000-0003-3872-9799, Rooney, J ORCID logoORCID: https://orcid.org/0000-0003-3638-5056 and Goodwin, PC (2016) To disclose or not to disclose? The workplace experience of physiotherapists with a specific learning disability. In: The 4th European Congress of the European Region of the World Confederation of Physical Therapy (ER-WCPT), 11 November 2016 - 12 November 2016, Liverpool, UK.

Downloaded from: https://e-space.mmu.ac.uk/354/

Version: Accepted Version

Publisher: Elsevier

DOI: https://doi.org/10.1016/j.physio.2016.10.013

Please cite the published version 


\section{To disclose or not to disclose? The workplace experiences of physiotherapists with a specific learning difficulty}

- G. Yeowell,

- J. Rooney,

- P.C. Goodwin

Relevance: This is a qualitative study, which investigates the experiences of physiotherapists working in the NHS in relation to having a specific learning difficulty. Better understanding of the issues faced by the physiotherapist in the workplace has the potential to impact on their practice making it relevant to Congress Theme 2 .

Purpose: To explore the workplace experiences of physiotherapists with a SpLD, in relation to disclosing their $\mathrm{SpLD}$, their support needs, and the impact on continuous professional development (CPD) and career progression.

Methods/analysis: This was Phase 2 of a 3-phase evaluation. The study was underpinned by the social model of disability. An exploratory qualitative design was undertaken to address the aim of the study. A purposive sample of eight qualified physiotherapists recognised as having a SpLD, were recruited. All participants studied on one of two programmes at a university in England between 2004 and 2012. Their NHS workplace experience was from across the UK. Participants were invited to take part by the investigators via Facebook and email. Ethical approval was obtained from Manchester Metropolitan University. Eight indepth interviews were undertaken with practising physiotherapists who had been diagnosed with a SpLD. All interviews were carried out by the same researcher (GY). Each interview lasted 40-70 minutes and was digitally recorded. An interview schedule was used to guide the interview. Interview data were transcribed verbatim and analysed using thematic analysis.

Results: Four participants were female. Participants were working as a Band $5(n=3)$ or Band $6(n=5)$ physiotherapist. Four main themes were identified:

1)Having dyslexia;

2)Disclosure;

3)Support and strategies;

4)NHS positive and negative responses.

Discussion and conclusions: 'Having dyslexia': Participants did not perceive themselves as having a disability; they perceived stigma was attached to the diagnosis. Participants indicated strengths and weakness related to their SpLD.

'Disclosure': Disclosure decisions were influenced by: perception of their SpLD being a disability; perceived stigma; fear of discrimination; levelling the playing field; support provided following disclosure; the guaranteed interview scheme; who they disclosed to, and previous experiences of disclosure/non-disclosure.

'Support and strategies': Some participants benefited from extra time to write up clinical notes. There was a lack of awareness regarding the UK Access to Work scheme. Their SpLD 
was not felt to impact on career progression. Several participants felt their SpLD did impact on $\mathrm{CPD}$, although they had developed strategies to lessen the influence of this.

'NHS positive and negative responses': Positive and negative responses were experienced following disclosure. Positive responses, for some, included managerial support in the workplace. Negative responses included: failure to disseminate to the wider team adjustments that had been put into place to support the participant's specific learning needs; and perceptions of being 'bullied' by the line manager.

Impact and implications: Better understanding the issues faced by the physiotherapist in the workplace has the potential not only to improve support mechanisms for the employee but also to facilitate the transition of physiotherapists with SpLD, from student to employee and back again.

Funding acknowledgement: Health Education Northwest (HENW). 